\title{
Modification of various metals by volume discharge in air atmosphere
}

\author{
Mikhail A. Shulepov ${ }^{1}$, Mikhail V. Erofeev ${ }^{1,2}$, Konstantin V. Oskomov ${ }^{1}$,Victor F. Tarasenko ${ }^{1,2 *}$ \\ ${ }^{1}$ Institute of High Current Electronics, SB, RAS, 634055, 2/3 Akademichesky Ave., Tomsk, Russia; \\ ${ }^{2}$ National Research Tomsk Polytechnic University, 634050, 30 Lenin Ave., Tomsk, Russia
}

\begin{abstract}
The results of the modification of stainless steel, niobium and titanium by volume discharge induced by a beam of runaway electrons in air under normal pressure are presented. Changes in the chemical composition of the surface layers of metal by the action of the discharge, structural changes and changes of hardness were studied. It has been found that the concentration of oxygen and carbon in the surface layers of the samples depend on the number of discharge pulses. The aim of this work is to find possible application of this type of discharge in science and industrial production.
\end{abstract}

Keywords: Volume discharge, surface modification, niobium, stainless steel, titanium.

\section{INTRODUCTION}

Methods of surface modification of various materials by electric current aimed at giving them new properties carried out for a long time with rather great success. All these methods can be divided into two big groups. Such methods as hydroelctric metallurgy and refining, where material processing take place in the special liquid - electrolyte, belong to the first group. These methods are dangerous for personal and environment, because, as usual, electrolytes are complex mixture of acids, salines which have high temperature and toxicity in operation.

The second group combined methods, where treatment of material is realized in some gas or vacuum by discharge plasma or ionlelectron beam. Ion implantation, molecular beam epitaxy and analysis method such as Auger spectroscopy can be relate to this group. These methods are more environmentally friendly and precise, but unfortunately very energy consuming. Recently studies and work under producing various surface coating by plasma chemical methods have been started. As an example we can cite the studies on nitriding of the surface of the titanium surface [1] or evaporation of heat-retaining coating on glass [2]. All these investigations and new methods of modification have the goal of generating new surface properties not typical of metals in the normal state.

Our laboratory have studied new type of gas volume discharge - runaway electron preionized diffuse discharge (REP DD) [3-5] since 2004. The REP DD does not require preionization of the gas and keeps uniform diffuse form at elevated pressures. Progress in generating of diffuse discharges initiated by runaway electrons allow us to study the possibilities of its application. Here we presents the results of our investigations of the REP DD surface modification of stainless steel $(12 \mathrm{X} 10 \mathrm{H} 8 \mathrm{~T})$, niobium and titanium in air atmosphere.

\section{EXPERIMENTAL EQUIPMENT AND PROCEDURE}

Studies of metals treatment by REP DD were carried out on generator RADAN-220, which has voltage pulse amplitude of $\sim 360 \mathrm{kV}$ (open circuit voltage) with pulse duration at matching load of $\sim 0.7 \mathrm{~ns}$ at FWHM for a rise time of $\sim 0.5 \mathrm{~ns}$. The measurements have shown that current amplitude was $\sim 3 \mathrm{kA}$, with total duration of discharge current of $\sim 13 \mathrm{~ns}$ (duration of first half-period of discharge current of $\sim 3 \mathrm{~ns}$ ) [4] (Fig. 1).

Samples treatment was carried out in pulse periodic mode with pulse repetition rate of $1 \mathrm{~Hz}$. A tube with diameter of $6 \mathrm{~mm}$ made of titanic foil with the thickness of $50 \mu \mathrm{m}$ was used as a cathode. Anode was a metal plates, polished and rinsed in the ultrasonic unit (Elmasonic S 10H, Elma-Hans Schmidbauer GmbH \& Co.) with distilled water and alcohol. After wiping, the sample was placed in the discharge chamber for the diffuse discharge plasma processing (see Fig. 2). The electrode gap was $18 \mathrm{~mm}$. Experiments on RADAN-220 were carried out in open chamber at ambient air of atmospheric pressure.

*VFT@1oi.hcei.tsc.ru; phone 83822 491-685; fax 83822 492-410; www.hcei.tsc.ru

International Conference on Atomic and Molecular Pulsed Lasers XII, edited by Victor F. Tarasenko,

Andrey M. Kabanov, Proc. of SPIE Vol. 9810, 98100X - (c) 2015 SPIE

CCC code: $0277-786 \mathrm{X} / 15 / \$ 18 \cdot$ doi: $10.1117 / 12.2224921$

Proc. of SPIE Vol. $981098100 X-1$ 


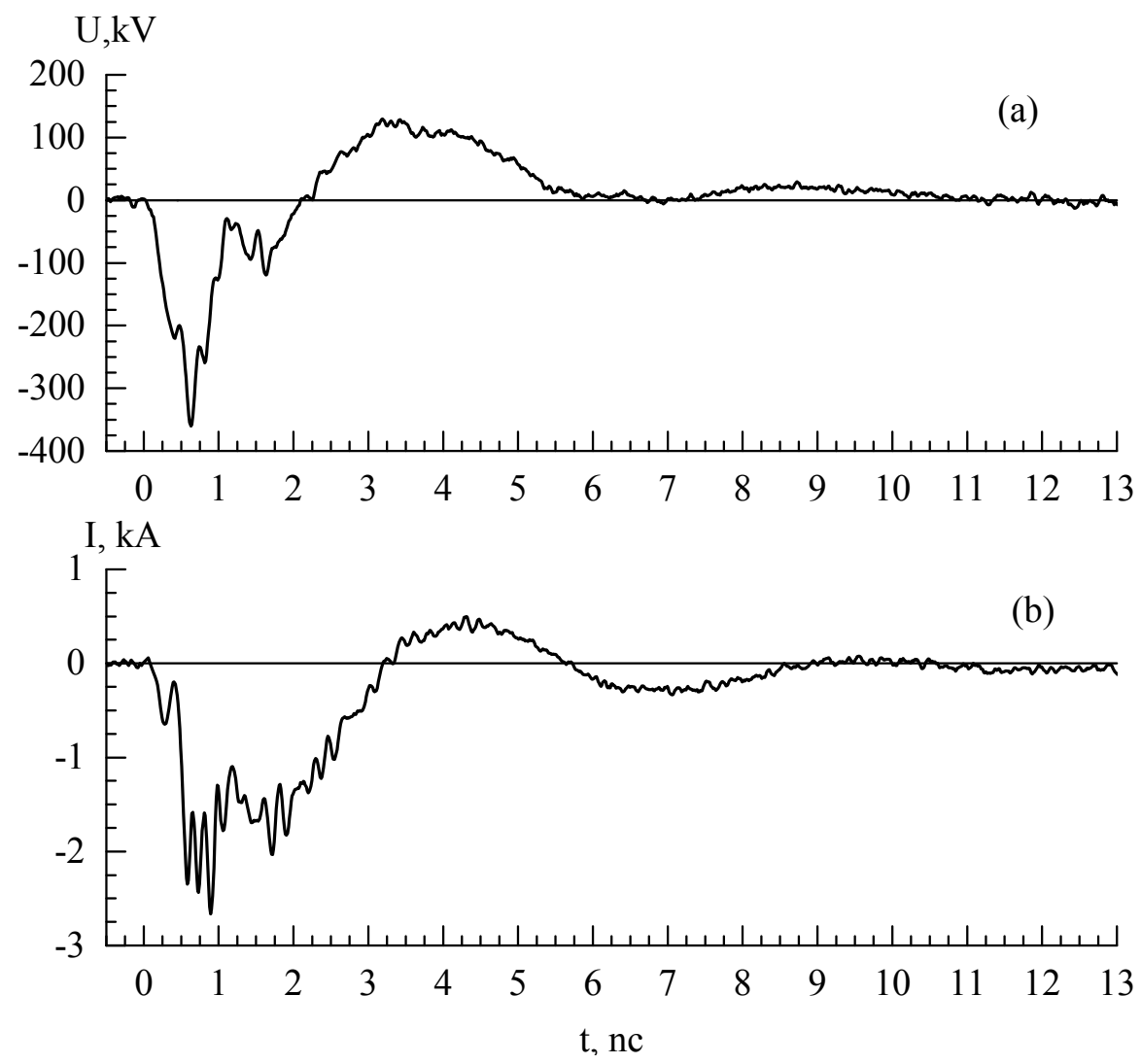

Figure 1. Oscilloscope traces of applied voltage pulse and discharge current.

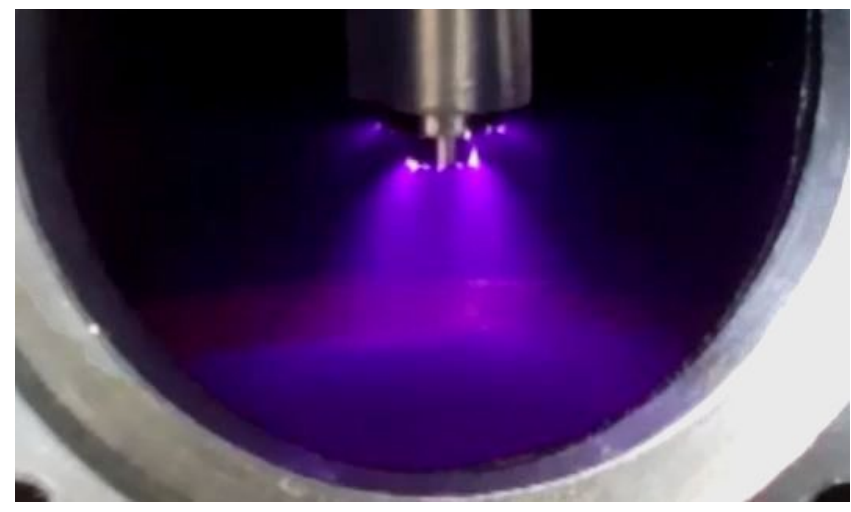

Figure 2. Photograph of volume discharge.

After discharge treatment, samples were placed in capsule filled with inert gas (argon) due to except influence of air, and were examined by Auger spectroscopy method on Shtil-2 spectrometer [6] for elemental composition of their surface.

\section{EXPERIMENTAL RESULTS}

\subsection{Modification of niobium surface by volume discharge in air atmosphere}

Results of the changes of chemical composition are shown on figure 3.

As can be seen, that oxygen concentration changed insignificantly on all scanned sample depth at small pulse numbers of discharge shots. Increasing of shot numbers to 3000 pulses leads to cover the sample surface with thin oxide film of $7 \mathrm{~nm}$ 

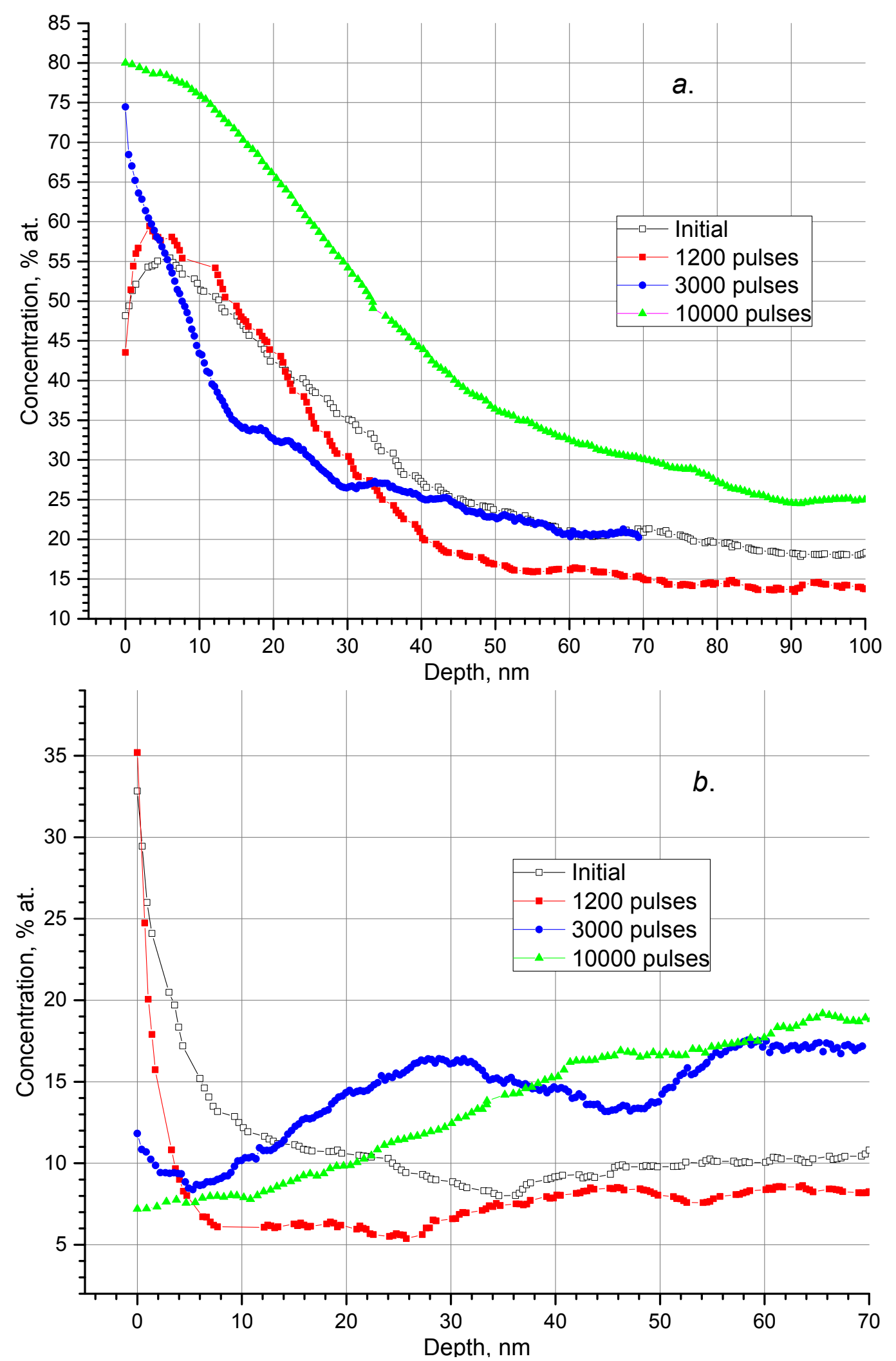

Figure 3. Dependence of the oxygen (a) and carbon (b) concentration in near-surface layers of niobium versus discharge pulses.

Proc. of SPIE Vol. 9810 98100X-3 
thickness. At the same time, oxygen concentration decreased within the surface layer from $7 \mathrm{~nm}$ until $40 \mathrm{~nm}$. After exposure to 10000 pulses, oxides concentration increased in the whole examined volume of the sample.

Studies of the changes under the REP DD action of carbon concentrations in near-surface layers of niobium samples give the results similar with ones obtained in our earlier experiments for another metals [7,8]. Under the low doses of treatment (1200 pulses), concentration of molecules containing carbon remains unchanged on the surface, but slightly decreased in the relief region (microcracks, scratches, roughness). There are inessential changes of carbon in the metal bulk. Increasing of the exposure to 3000 and 10000 pulses leads to the better cleaning of the surface from the carbon containing contaminations. Thus, carbon concentration decreases $\sim 4$ times in a surface layer up to $5 \mathrm{~nm}$.

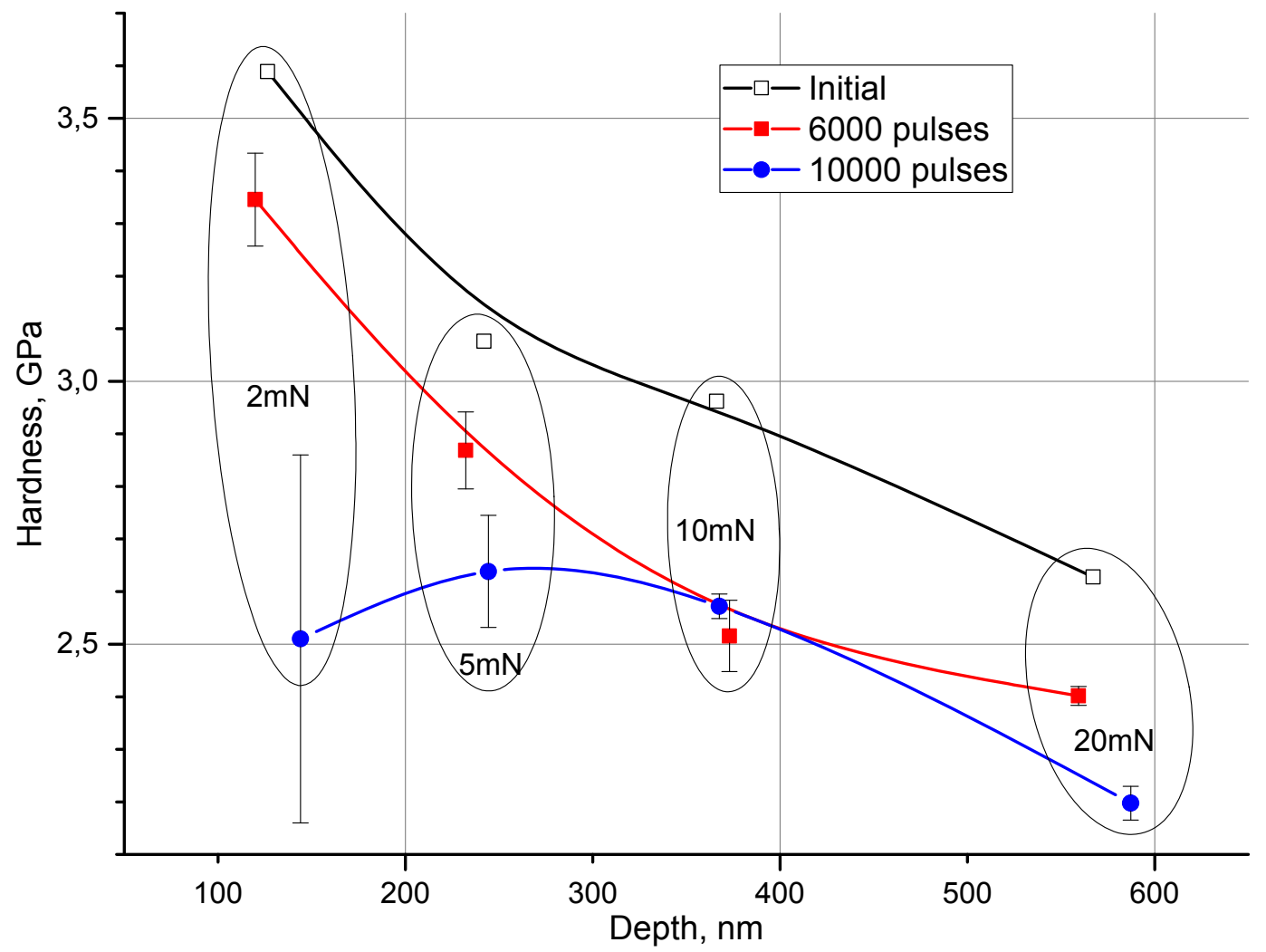

Figure 4. Dependence of the nano-hardness of niobium versus depth for different loads.

Studies of nano-hardness of the treated samples have shown that the hardness of niobium surface layers decreased with increasing of exposure dose (see Fig. 4), that is the opposite of results for copper and steel obtained in the early experiments in which the hardness increased [7,9]. Obviously, it concerned with the fact that niobium oxides are more porous in comparison with the pure niobium.

\subsection{Modification of stainless steel surface by volume discharge in air atmosphere}

Study of element composition of stainless steel surface after REP DD treatment is presented on Fig. 5 and does not look such unambiguously like in the case of niobium. Here can be clearly seen two groups of results.

In the first one there are samples treated by 1200 and 3000 pulses. It is seen, that the concentration of oxides in the relief region up to $30 \mathrm{~nm}$ practically unchanged, difference of the values lies in the region of error measurements. However, the situation changes in the alloy bulk. In the case of exposure to 1200 pulses of discharge, saturation by oxygen takes place in the surface layer, and after exposure to 3000 pulses oxygen concentration decreased drastically (almost in 3 times) at a depth lager than $30 \mathrm{~nm}$.

The second group of results combines exposure doses of 250 and 6100 discharge pulses. Despite of the appreciably difference in doses, changes of the oxygen concentration very close to each other. As opposite [8], in these experiments cleaning from oxygen occurs on the surface and in the bulk. 

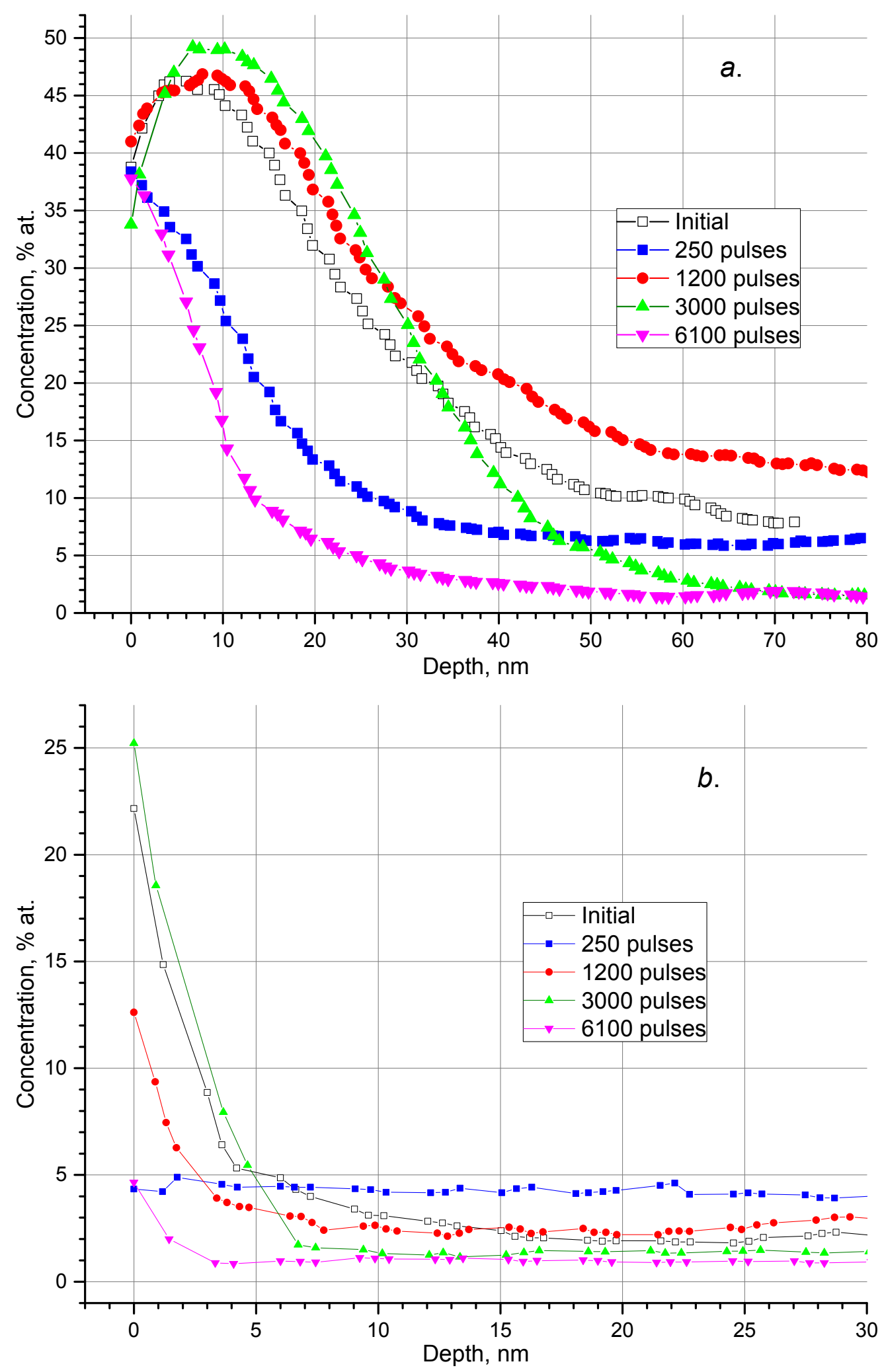

Figure 5. Dependence of the oxygen (a) and carbon (b) concentration in near-surface layers of stainless steel versus discharge pulses.

Proc. of SPIE Vol. $981098100 X-5$ 
Changes of the carbon concentration after discharge treatment also can be divided into two groups. As in the case of oxygen, there are samples treated with exposure to 1200 and 3000 discharge pulses in the first group. Here concentration of carbon remained unchanged (after 3000 pulses) or occurred insignificant cleaning of the surface (after 1200 pulse). In the second group, samples after exposures to 250 and 6100 pulses have substantial surface cleaning - carbon concentration decreased up to 5 times.

It is interesting to note, that in spite of distinction in dependences of stainless steel elements concentration from that one of carbon steel, changes of nano-hardness of $12 \times 10 \mathrm{H} 8 \mathrm{~T}$ steel versus sample depth after different treatment doses are similar to its changes in ST3 [8]. Nano-hardness after discharge treatment on average increased up to 2 times, see figure 6.

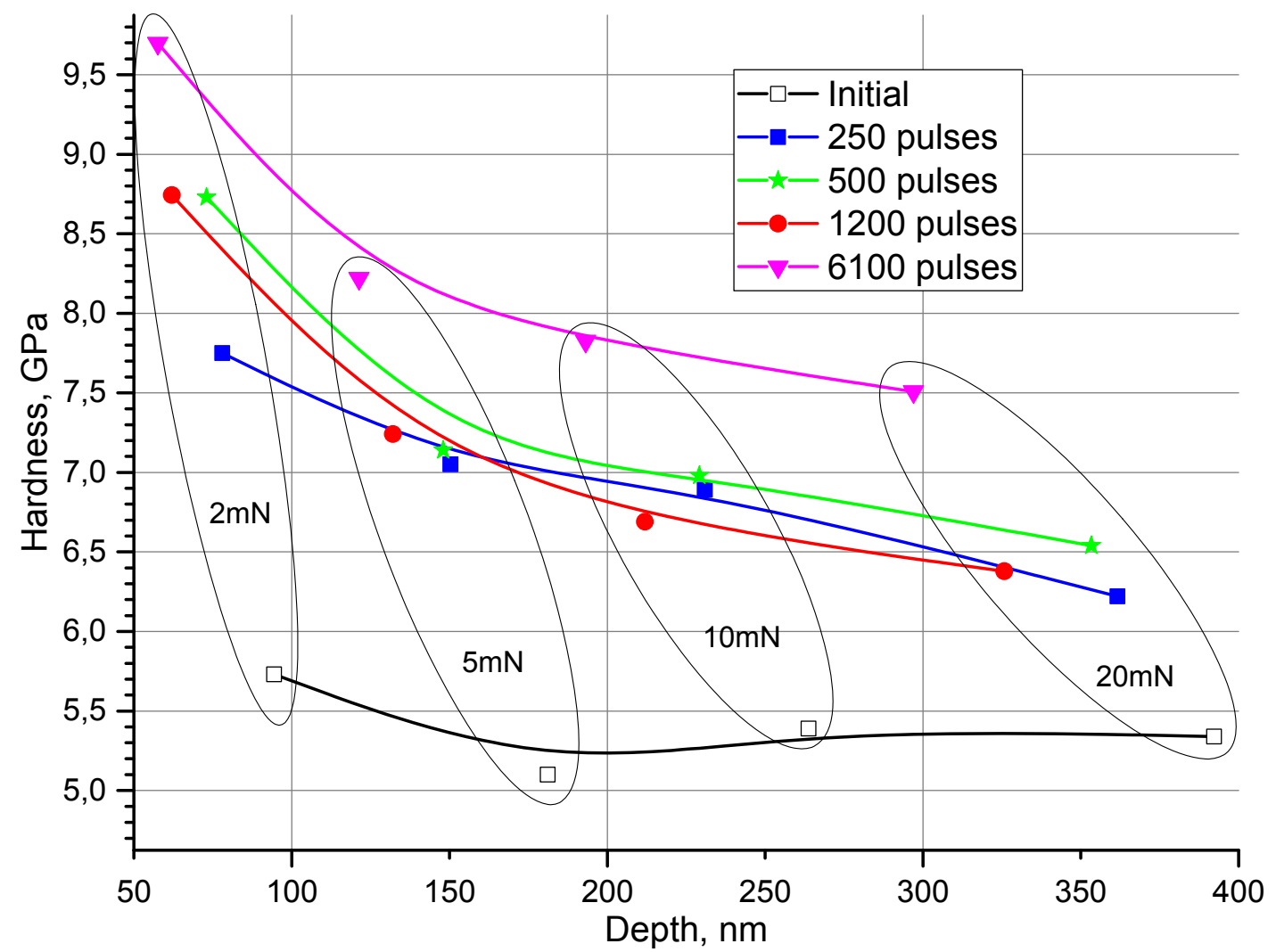

Figure 6. Dependence of the nano-hardness of stainless steel versus depth for different loads.

\subsection{Modification of titanium surface by volume discharge in air atmosphere}

Figure 7 shows changes of elements concentrations in different depths of titanium samples treated by REP DD, which were obtained by using the Auger electron spectroscopy. As can be seen from the figure, the volume discharge treatment has weak impact on titanium surface modification in spite of different number of discharge shots. In the surface layers at a depth of up to 40-60 nm, the oxygen concentration slightly increased, however in deeper layer it decreased.

Surface cleaning from the carbon contaminations takes place not only on the surface, but also into the bulk volume (the case of the sample treated by 1200 pulses). 

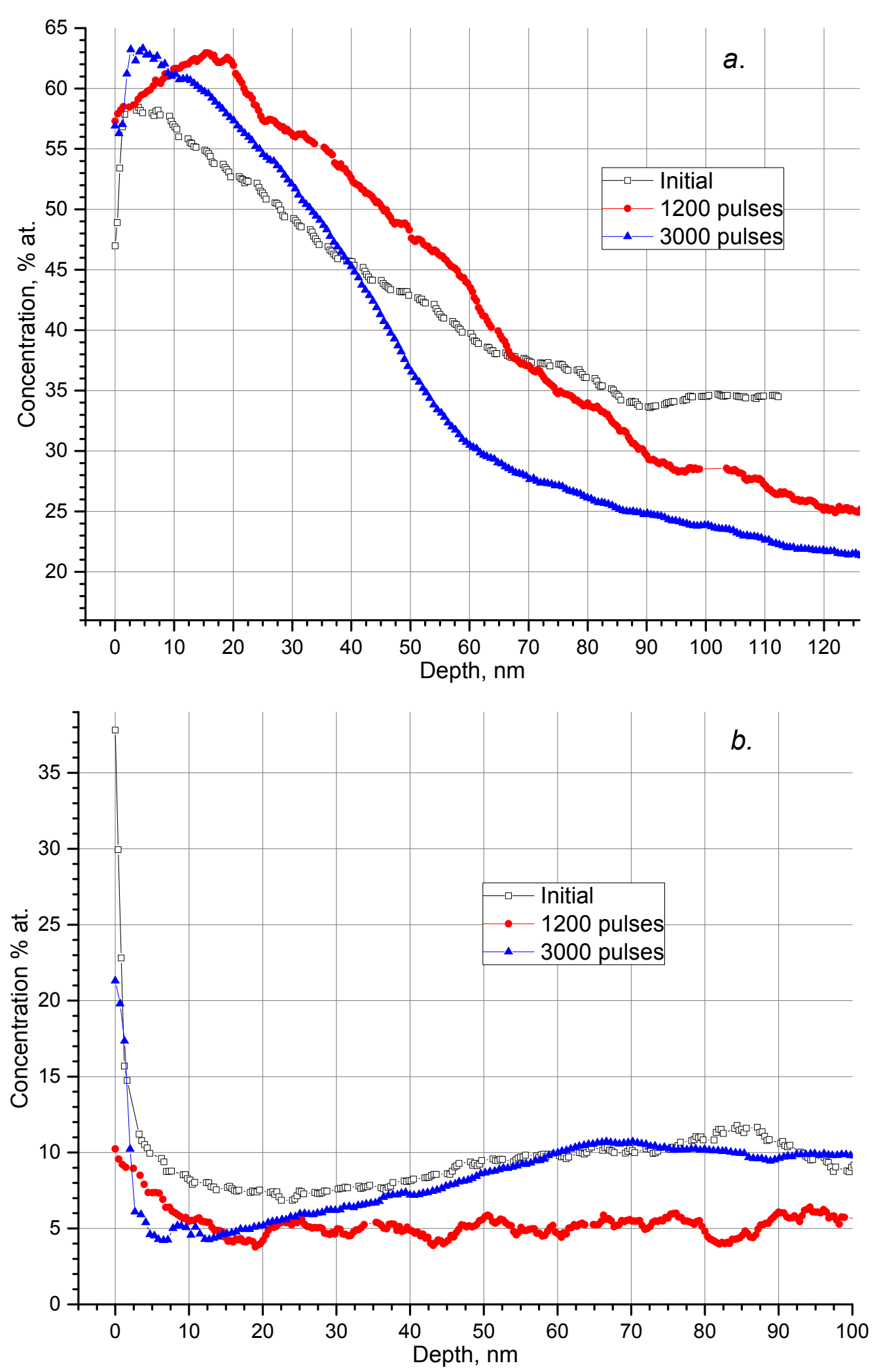

Figure 7. Dependence of the oxygen (a) and carbon (b) concentration in near-surface layers of titanium versus discharge pulses.

Proc. of SPIE Vol. $981098100 X-7$ 
Results of the measurements of nano-hardness of the treated samples have shown ineffective action of REP DD on titan, see figure 8 .

Only sample treated by 1200 discharge pulses has insignificant increasing of hardness. On exposure to 3000 pulses, hardness of the sample decreased with regard to the initial one. Because changes of the carbon concentration could not effect on the surface hardness and admixtures of other elements are negligible, it can be stated, that only changes of the oxygen concentration can be the reason of the hardness changes.

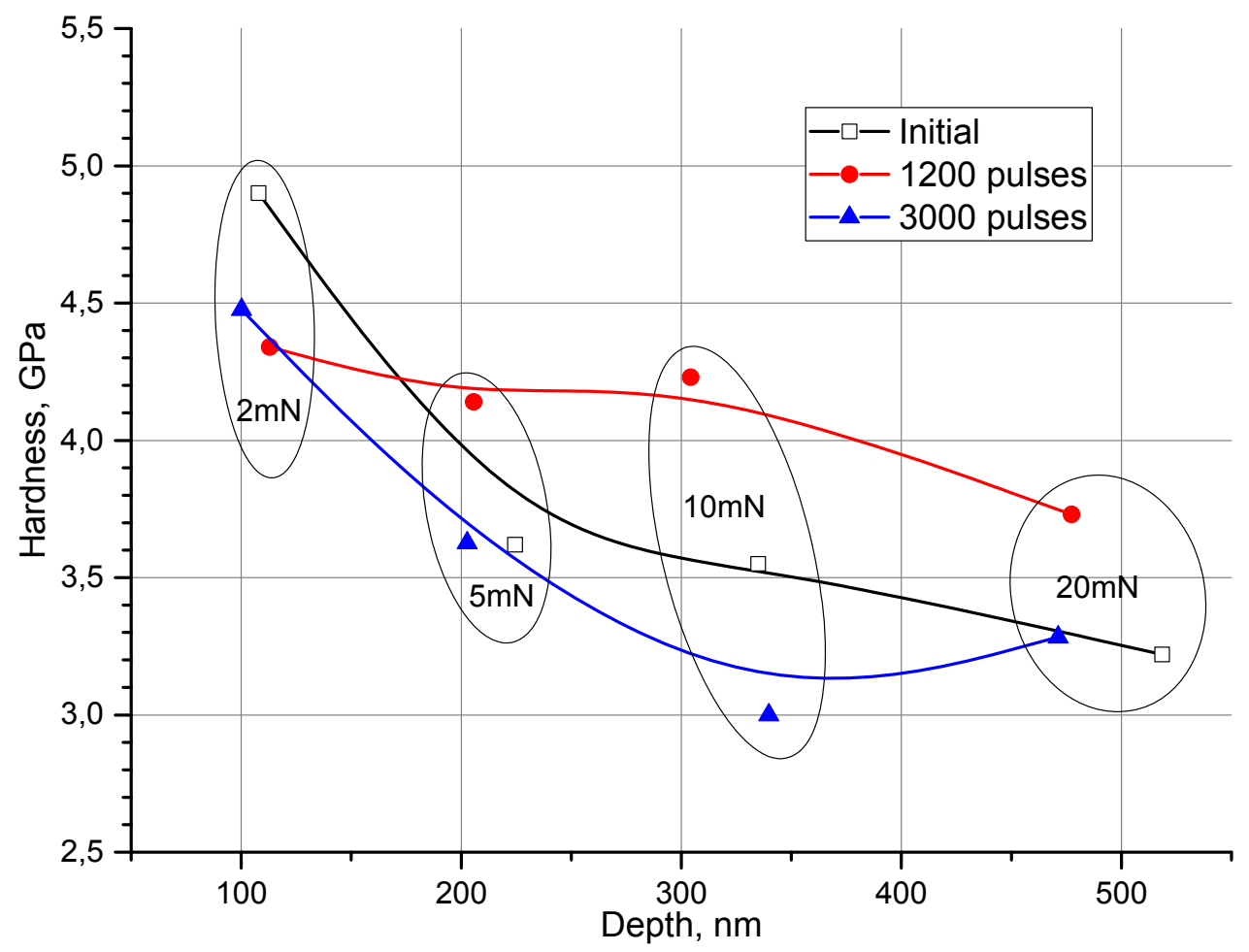

Figure 8 . Dependence of the nano-hardness of titanium versus depth for different loads.

\section{CONCLUSIONS}

Thus experimental results show that REP DD effectively modify relief of the surfaces of metals till the depth where metal bulk begin. In the main cases of metals under study (steel ST3, stainless steel, copper, aluminum, niobium, titanium) after discharge treatment in air atmosphere, oxygen penetration to the surface layers as well as its cleaning from carbon contaminations take place. In all cases, except aluminum, hardening of the metal surface layer have been found. The cases when after treatment de-oxidation from relief and/or bulk of the processed metal were registered. In such cases hardness of the surface layers decreased in comparison of the initial metal, but the cleaning from the carbon contaminations took place every time.

\section{ACKNOWLEDGMENTS}

The work is performed in the framework of the Russian Science Foundation (Project No. 14-29-00052).

\section{REFERENCES}

[1] Koval', N. N., Gromov, V. E., [Modern Trends in Modification of Materials Structure and Properties], NTL, Tomsk, 380 (2015). 
[2] Ladyzhensky, O. B., Zaslavsky, V. M., Kovsharov, N. F., Rasputin, R. M., Sochugov, N. S., "Ion beam treatment of glass surfaces as a method for increased metal film adhesion," Laser Part. Beams, 21(2), 291-293 (2003).

[3] Tarasenko, V. F., Orlovskii, V.M., Shunailov, S. A., "Forming of an electron beam and a volume discharge in air at atmospheric pressure," Russ. Phys. J., 46(3), 325-327 (2003).

[4] Baksht, E. Kh., Burachenko, A. G., Kostyrya, I. D., Lomaev, M. I., Rybka, D. V., Shulepov, M. A., Tarasenko, V. F., "Runaway-electron-preionized diffuse discharge at atmospheric pressure and its application," J. Phys. D. Appl. Phys., 42(18), 185201 (2009).

[5] Tarasenko, V. F., [Runaway Electrons Preionized Diffuse Discharges], Nova Science Publishers Inc., New York, 598 (2014).

[6] Shulepov, I. A., [Development and application of combined atomic and nuclear physics methods for examining modified layers of materials] , $\mathrm{PhD}$ thesis, Tomsk, 141 (2004).

[7] Shulepov, M. A., Akhmadeev, Y. K., Tarasenko, V. F., Kolubaeva, Y., A. Krysina, O. V. and Kostyrya, I. D., "Modification of surface layers of copper under the action of the volumetric discharge initiated by an avalanche electron beam in nitrogen and CO2 at atmospheric pressure," Russ. Phys. J., 53(12), 1290-1294 (2011).

[8] Shulepov, M. A., Erofeev, M. V., Ivanov, Y. F., Oskomov, K. V., Tarasenko, V. F., "Action of runaway electron preionized diffuse discharge on steel: composition, structure, and properties," J. Phys. Sci. Appl., 15, 33-37 2015.

[9] Shulepov, M. A., Tarasenko, V. F., Goncharenko, I. M., Koval', N. N., Kostyrya, I. D., "Modification of the near-surface layers of a copper foil under the action of a volume gas discharge in air at atmospheric pressure," Tech. Phys. Lett., 34(4), 296-299 (2008). 